\title{
Spousal violence against women and its consequences on pregnancy outcomes and reproductive health of women in India
}

\author{
Mahadev Bramhankar ${ }^{*}$ and R. S. Reshmi
}

\begin{abstract}
Background: Globally, one in three women experienced domestic violence. Alike the scenario observed in India, and a very few studies talk about violence and its consequences on women's health. Hence, the purpose of this study is to access the level of various types of spousal violence in India and to understand the association between physical, sexual and emotional violence against ever-married women by their husbands. The study further examines the consequences of spousal violence on women's health in terms of adverse pregnancy outcomes and reproductive health in India.

Methods: The study uses secondary data from National Family Health Survey-4 (NFHS-4, 2015-16). The analysis was based on a sample of ever-married women aged 15-49 years. Bivariate descriptive analysis and multiple regression analyses have been carried out to understand the association between spousal violence and its consequences on women's health.

Results: The study finds that the physical, sexual and emotional violence experienced by ever-married women in India are 29.8\%, 13.8\% and 7.0\%, respectively. Further, the physical and sexual violence experienced by women have a significant association with an unwanted pregnancy, abortion, miscarriages and ever had termination of pregnancies. The regression analysis shows that violence by sexual partners among battered women increased the likelihood of unwanted pregnancy. Similarly, abortion and ever had a termination of pregnancies are also adversely affected by partner violence. Further, the risk of sexually transmitted infection increases $77 \%$ by sexual violence and $44 \%$ by emotional violence among battered women. Also, Sexual violence substantially increases the risk of prolonged labour during pregnancy.
\end{abstract}

Conclusion: This study revealed that one in three women experiencing violence by their husband and also it is evident that various forms of spousal violence adversely affect pregnancies outcomes and reproductive health among battered women compared to not battered.

Keywords: Adverse pregnancy outcome, Reproductive health, Spousal violence, Sexual violence, Physical violence

\section{Introduction}

A multi-country study done by the World Health Organization (WHO) revealed that physical violence ranged

*Correspondence: bramhankarakash@gmail.com

Department of Migration and Urban Studies, International Institute

for Population Sciences (IIPS), Mumbai 400088, India from $12.6 \%$ in Japan to $61 \%$ in Peru. Ethiopia and Peru have a substantial prevalence of sexual violence, ranging from 48 to $59 \%$, whereas Japan has the lowest pervasiveness [1]. In India, 33\% of the ever-married women aged 15-49 experienced physical violence, $7 \%$ had experienced sexual violence, and $13 \%$ had the experience of emotional violence by their current or former husband throughout 
married life [2]. According to the existing literature, one of the adverse effects of spousal violence could be unintended pregnancy, as those women might suffer from sexual violence and be afraid to ask or discuss contraception with their husbands [3]. The same study also stated that prevalence of unintended pregnancy is higher among physically battered women by a partner. Women experiencing physical violence by the husband were more likely to report the risk of unwanted pregnancies resulting in a live birth [4]. Another study of pregnant women of the postpartum period in Peru found that $65 \%$ of the pregnancies were unintended. Those who experienced any life abuse (physical or sexual) had a higher risk of unintended pregnancies [5].

According to an estimates of the WHO, maternal deaths and 4.6 million disability-adjusted life year (DALYs) could prevent worldwide causes if they avert unintended pregnancies [6]. Another study showed a significant positive relation between spousal violence and unintended pregnancy [7]. Further, in the context of patriarchal municipalities found that women living in municipalities with higher intimate spousal violence levels had the risk of almost three times the odds of having unintended pregnancies [8]. Nearly one fourth of the married women reported having experienced an unintended pregnancy in the last five years of the survey. The same study also reported that among ever battered women by their husbands' sexual form of violence were 2.3 times higher chances of unintended pregnancy than women who did not experience sexual violence [9]. Perhaps another study showed that miscarriages were more exposure in the physically battered women than sexually battered women as they would fall, beaten or threatened at the time of pregnancy. A study done by Kishor and Jonhson [10], reported that spousal violence positively associated with the probability of poor reproductive outcomes when wealth and other factors are held constant. Among the ever pregnant women, 23\% experienced involuntary pregnancy loss, while $7 \%$ reported induced abortion among those who had exposure to intimate spousal violence [11]. Intimate Partner Violence (IPV) affected woman's physical and reproductive health, reduced sexual autonomy, and increased risk of unintended pregnancy and abortions [12].

Similarly, the study by Silverman [13, 14], reveals that adjusted regressions results significant associations between miscarriage and IPV Adjusted Odds Ratio $(\mathrm{AOR}=1.35,95 \% \mathrm{CI}=(1.11,1.65)$ and stillbirth $(\mathrm{AOR}=1.36,95 \% \mathrm{CI}=(1.02,1.82)$ ever, as well as with labour complications with AOR 1.27 [13, 14]. Women who reported physical and sexual violence were 1.7 times more likely to report gynecologic morbidity [15]. For the several clinical based studies conducted in various part of the globe especially developing regions indicates a strong association of intimate spousal violence and symptoms of Sexually Transmitted Infection (STI) with reproductive health problems [16]. Another study in Vietnam that shore up confirms the relationship between experiencing violence and being at high risk of STI and HIV. The estimated proportions of intimate partner violence (IPV) during pregnancy ranged from $5.9 \%$ to $32.5 \%$. Depending on the form of IPV, it is strongly associated with a greater risk of both mental disorders and adverse birth outcomes (low-birth-weight and preterm labour) [17]. Ever married women who experienced violence have self-reported poor reproductive health compared with not battered women [16]. In Bangladesh, women who experienced sexual IPV during pregnancy were at increased risk of suffering from IPV during pregnancy are positively associated with pregnancy complications [18].

There are many studies that reported the relation between women who experienced violence and adverse pregnancy outcomes and reproductive health faced by married women. Even though very few studies address this problem in the Indian context. The nationally representative NFHS-4 data has opened the window of opportunity for scientific investigation of battered women through various socio-demographic, economic and other characteristics. Therefore, the present study focuses on the attributable effect of spousal violence on ever-married women's pregnancy outcomes and reproductive health. In the present study, firstly we estimate the prevalence of various types of spousal violence across the different socio-demographic characteristics and also states wise differential for the ever-married women aged 15-49 years in India. Moreover, the secondary objective of this study is to explore the association of physical, sexual and emotional spousal violence on adverse pregnancy outcomes and reproductive health of Indian women.

\section{Material and methods}

This study is based on a large scale cross-sectional survey well known nationally representative data of the National Family Health Survey fourth round (NFHS-4). The NFHS is also referred to as the Demographic Health Survey (DHS) in other countries' perspectives. It is conducted regularly in many developing countries to obtain population-based estimates of major health issues, family planning and violence-related information collected from various countries. Data was collected for NFHS-4 in all 29-states and seven union territories during the 2015-2016 period. In India, NFHS-4 gives information at the district level, but the survey included a section on 'Domestic Violence', representing the state level. The information was collected from only one woman per each household. The present study restricted the 
sample of ever-married women aged 15-49 years, including currently married, divorced, separated, widowed, and no longer living together. The sample size related to spousal after giving weight, the ultimate sample related to spousal violence was 61,906 ever-married women. The term 'domestic violence' module of the NFHS-4, spousal violence, uses a modified version of the Conflict Tactics Scales (CTS) [19, 20]. The same study includes questions that have asked women whether their current or most recent (if divorced, separated, or widowed) husband/ partner ever perpetrated any series of behaviorally specific acts of physical, emotional, or sexual violence. Those who reported that they ever experienced any violence have been categorized as any experienced of spousal violence by husband or partner.

\section{Definitions of key measures used in the analysis}

The present study uses various types of spousal violence, such as physical violence, emotional violence, sexual violence, and any violence which are defined here, according to the given Demographic Health Programmed criteria [21]. For the computation of physical violence, a set of seven-question were asked to ever-married women. If a woman reported that they experienced any of the following experienced by women by husband or partner considered as a case of physically abused women, and the questions were such that: (a) Slap you?, (b) Twist your arm or pull your hair?, (c) Push you, shake you, or throw something at you?, (d) Punch you with his fist or with something that could hurt you? (e) Kick you, drag you or beat you up? (f) Try to choke you or burn you on purpose? (g) Threaten or attack you with a knife, gun, or any other weapon?. Similarly, for the computation of Emotional violence, asked three questions to the ever-married women have asked: (a) Say or do something to humiliate you in front of others? (b) Threaten to hurt or harm you or someone close to you? (c) Insult you or make you feel bad about yourself? If one of the answers positively responds to women considered as a case of emotional violence. Further, for the computation of sexual violence, three-question responses were asked, (a) Ever been physically forced into unwanted sex by husband/partner? (b) Ever been forced into other unwanted sexual acts by husband/partner? Ever been physically forced to perform sexual acts respondent didn't want?. Based on the aforementioned different types of violence, another term called any spousal violence is a combination of any kind of physical or emotional or sexual violence experienced by women in their married life.

In our study, the information about abortion, and miscarriages have collected from those women who had a history of pregnancy in the last five year. For the prolonged labour problem, the question "During delivery, did you experience prolonged labour?" was asked to the respondent who has history of pregnancies in last five years. Further, the information about ever termination of pregnancy was asked to all married women in the age group 15-49. This study also signifies the problem of reproductive health which was considered as a Sexually Transmitted Infection (STI) in the last 12-months reported by all ever-married women. Furthermore, in the study, additional explanatory factors considered as derived from prior literature included as the residence, age group, religion, socio-economic status, caste, intergenerational violence, children ever born, contraception use and their education [11, 22, 23].

The present study examine the association among various factors, descriptive statistics and possible associations between factors were explored by conducting cross-tabulations. Further, the multivariate logistic regressions were used to obtain adjusted odds ratios (AORs) by controlling for the more commonly recognized explanatory factors using household characteristics such as residence, wealth index, religion and caste. The P-value below 0.05 was considered statistically significant, at $95 \%$ of the confidence interval. An odds ratio larger than one represents a greater likelihood of the outcome than for the reference category and vice-versa for multiple logistic regression results. Using STATA version. 15 and Excel software were used for data analysis.

\section{Results}

Table 1(a) and (b) gives the prevalence of various form of spousal violence by their household and socio-economic and demographic characteristics. It is evident from the table that, in India, $29.8 \%$ of the women reported physical violence, $13.8 \%$ reported emotional violence and $7 \%$ reported sexual violence and the prevalence of any of these violence was 33.3\%. Further, as shown in Fig. 1, the prevalence of spousal violence ranged from 3.5 to $55 \%$ across the states and union territory, showing ta significant difference in the level of spousal violence across the country. Manipur has the highest, and Sikkim has the lowest prevalent of spousal violence in India. The household characteristics such as type of place of residence, wealth, caste, and religion were significantly associated with the various forms of violence, on the same line, intimate spousal violence related to women's individual-level characteristics in India.

Table 2, indicates the association between various types of spousal violence and health problem experienced by women in India. It revealed that the proportion of women who reported abortion and miscarriages are $4 \%$ and $5.7 \%$ respectively. Similarly, nearly one fifth of the women reported that they ever had terminated pregnancy. Among the currently pregnant women, $12.3 \%$ has 
Table 1 Prevalence of various type of spousal violence among ever-married women and its association with (a) household characteristics, (b) women characteristics

\begin{tabular}{|c|c|c|c|c|c|}
\hline & Physical violence & Emotional violence & Sexual violence & Any violence & $\mathrm{n}$ \\
\hline \multicolumn{6}{|l|}{ (a) Household characteristics } \\
\hline Place of residence & $* * *$ & $* * *$ & $* * *$ & $* * *$ & \\
\hline Urban & 24.3 & 12.0 & 5.2 & 27.7 & 21,461 \\
\hline Rural & 32.7 & 14.8 & 7.9 & 36.3 & 40,445 \\
\hline Wealth Index & $* * *$ & $* * *$ & $* * *$ & $* * *$ & \\
\hline Poorest & 42.2 & 19.2 & 11.6 & 46.0 & 10,550 \\
\hline Poorer & 36.8 & 16.5 & 8.4 & 40.7 & 11,974 \\
\hline Middle & 31.4 & 15.0 & 7.1 & 35.3 & 12,793 \\
\hline Richer & 25.7 & 12.0 & 5.3 & 29.1 & 13,140 \\
\hline Richest & 16.2 & 8.0 & 3.5 & 19.1 & 13,449 \\
\hline Religion & $* * *$ & $* * *$ & $* * *$ & $* * *$ & \\
\hline Hindu & 30.5 & 14.0 & 7.0 & 34.0 & 50,215 \\
\hline Muslim & 27.1 & 14.1 & 6.7 & 31.5 & 8449 \\
\hline Christians & 28.8 & 14.0 & 7.2 & 33.3 & 1474 \\
\hline Others & 21.8 & 7.9 & 6.5 & 23.3 & 1769 \\
\hline Caste & $* * *$ & $* * *$ & $* * *$ & $* * *$ & \\
\hline Schedule caste (SC) & 37.1 & 17.4 & 9.1 & 40.6 & 12,050 \\
\hline Schedule tribe (ST) & 32.7 & 15.6 & 8.7 & 36.5 & 5684 \\
\hline $\mathrm{OBC}$ & 30.8 & 14.1 & 6.8 & 34.6 & 27,350 \\
\hline Others & 21.9 & 10.3 & 5.1 & 25.0 & 16,823 \\
\hline India & 29.8 & 13.8 & 6.96 & 33.3 & 61,906 \\
\hline \multicolumn{6}{|l|}{ (b) Women's characteristics } \\
\hline Age Interval & $* * *$ & $* * *$ & $* * *$ & $* * *$ & \\
\hline $15-24$ & 24.19 & 11.98 & 6.41 & 11.98 & 11,356 \\
\hline $25-34$ & 30.32 & 13.55 & 7.24 & 13.55 & 22,967 \\
\hline $35-44$ & 31.59 & 14.59 & 6.98 & 14.59 & 19,164 \\
\hline $45-49$ & 31.70 & 15.41 & 6.91 & 15.41 & 8418 \\
\hline Children ever born & $* * *$ & $* * *$ & $* * *$ & $* * *$ & \\
\hline 0 & 18.6 & 11.6 & 5.7 & 23.0 & 6123 \\
\hline 1 & 23.1 & 12.1 & 6.0 & 26.3 & 11,407 \\
\hline 2 & 28.8 & 12.8 & 5.9 & 32.1 & 20,198 \\
\hline $3+$ & 36.6 & 16.1 & 8.7 & 40.3 & 24,178 \\
\hline Women's education & $* * *$ & $* * *$ & $* * *$ & $* * *$ & \\
\hline No education & 39.7 & 18.4 & 9.4 & 43.6 & 20,114 \\
\hline Primary & 36.5 & 15.8 & 8.5 & 39.7 & 8847 \\
\hline Secondary & 24.1 & 11.5 & 5.6 & 27.8 & 26,522 \\
\hline Higher & 12.8 & 6.3 & 2.9 & 15.0 & 6423 \\
\hline Current marital status & $* * *$ & $* * *$ & $* * *$ & $* * *$ & \\
\hline Married & 29.2 & 13.2 & 6.7 & 32.8 & 58,480 \\
\hline Widowed & 29.9 & 14.3 & 8.5 & 31.9 & 2477 \\
\hline Divorced & 60.9 & 54.2 & 24.8 & 65.8 & 289 \\
\hline No longer living together & 68.5 & 54.5 & 21.1 & 75.4 & 661 \\
\hline Intergenerational Violence & $* * *$ & $* * *$ & $* * *$ & $* * *$ & \\
\hline No & 23.2 & 10.6 & 5.1 & 26.3 & 46,780 \\
\hline Yes & 53.1 & 25.4 & 13.5 & 57.7 & 13,011 \\
\hline Don't know & 33.1 & 13.8 & 7.5 & 38.2 & 2115 \\
\hline Contraception use & $* * *$ & ** & * & $* * *$ & \\
\hline Not using & 28.0 & 14.0 & 7.3 & 31.9 & 28,507 \\
\hline Using & 31.3 & 13.7 & 6.7 & 34.5 & 33,399 \\
\hline
\end{tabular}


Table 1 (continued)

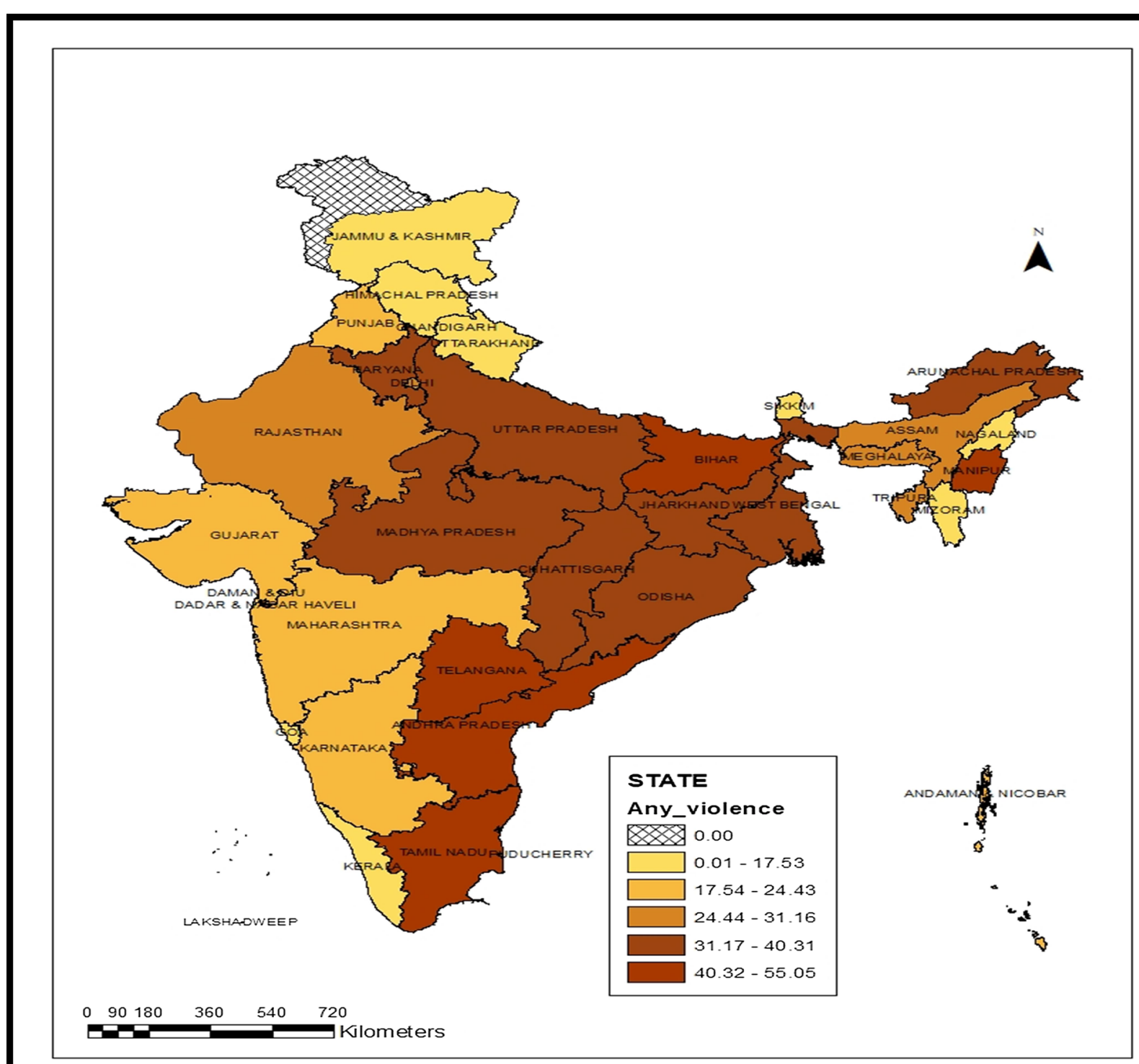

Fig. 1 Any type of violence across states of India (\%), NFHS-4 (2015-16). Note: The data for Jammu \& Kashmir area was not available which showed by cross line in this figure

reported to have unwanted pregnancy. The prevalence of STI among women was $2.43 \%$ in the last 12 months of the survey. Furthermore, $42.3 \%$ of women experienced prolonged labour during pregnancy. Table 2 shows that the currently unwanted pregnancy, abortion and ever had a termination of pregnancies have a strong association with physical, emotional, sexual violence.
The multivariate logistic regression model was adjusted by household characteristics given in the Table 3. The result shows, (AOR 1.72, 95\% CI 1.19, 2.5), that the likelihood for the unwanted pregnancy was higher among women who experienced any sexual violence. Unwanted pregnancy was comparatively higher among women who experienced sexual violence as compared to those 
Table 2 Percentage of adverse pregnancy outcome, sexual and reproductive health among ever-married women in age group 15-49 and its association with various forms of spousal violence

\begin{tabular}{|c|c|c|c|c|c|c|c|c|c|c|c|c|}
\hline \multirow{2}{*}{$\begin{array}{l}\text { Exposure of violence } \\
\text { Spousal violence }\end{array}$} & \multicolumn{2}{|c|}{$\begin{array}{l}\text { STI (in last } \\
12 \text { months) }\end{array}$} & \multicolumn{2}{|c|}{$\begin{array}{l}\text { Current } \\
\text { unwanted } \\
\text { pregnancy }\end{array}$} & \multicolumn{2}{|c|}{ Abortion } & \multicolumn{2}{|c|}{ Miscarriage } & \multicolumn{2}{|c|}{$\begin{array}{l}\text { Ever had a } \\
\text { termination of } \\
\text { pregnancy }\end{array}$} & \multicolumn{2}{|c|}{$\begin{array}{l}\text { Prolonged } \\
\text { labour during } \\
\text { pregnancy }\end{array}$} \\
\hline & (\%) & $\mathrm{n}$ & (\%) & $n$ & (\%) & $\mathrm{n}$ & (\%) & $\mathrm{n}$ & (\%) & $\mathrm{n}$ & (\%) & $n$ \\
\hline Physical & $* * *$ & & $* * *$ & & $* * *$ & & * & & $* * *$ & & $* * *$ & \\
\hline No & 2.25 & 43,472 & 11.05 & 2698 & 3.0 & 16,026 & 5.65 & 16,026 & 14.53 & 43,472 & 40.58 & 15,127 \\
\hline Yes & 2.83 & 18,435 & 16.18 & 836 & 5.0 & 6755 & 5.91 & 6755 & 20.34 & 18,435 & 47.49 & 6306 \\
\hline Emotional & $* * *$ & & $* * *$ & & $* * *$ & & $* *$ & & $* * *$ & & $* * *$ & \\
\hline No & 2.24 & 53,341 & 11.68 & 3114 & 3.3 & 19,737 & 5.49 & 19,737 & 15.45 & 53,341 & 41.53 & 18,630 \\
\hline Yes & 3.59 & 8565 & 16.61 & 420 & 5.7 & 3044 & 7.26 & 3044 & 21.33 & 8565 & 49.85 & 2803 \\
\hline Sexual & $* * *$ & & $* * *$ & & $* * *$ & & * & & $* * *$ & & $* * *$ & \\
\hline No & 2.28 & 57,597 & 11.54 & 3302 & 3.4 & 21,091 & 5.82 & 21,091 & 15.79 & 57,597 & 42.03 & 19,873 \\
\hline Yes & 4.37 & 4309 & 22.52 & 231 & 6.3 & 1690 & 4.61 & 1690 & 22.63 & 4309 & 50.09 & 1560 \\
\hline Any violence & $* * *$ & & $* * *$ & & $* * *$ & & $* *$ & & $* * *$ & & $* * *$ & \\
\hline No & 2.17 & 41,278 & 10.62 & 2542 & 2.9 & 15,236 & 5.55 & 15,236 & 14.31 & 41,278 & 40.18 & 14,404 \\
\hline Yes & 2.95 & 20,628 & 16.46 & 992 & 4.9 & 7545 & 6.08 & 7545 & 20.17 & 20,628 & 47.60 & 7029 \\
\hline India & 2.43 & 61,906 & 12.26 & 3534 & 4 & 22,781 & 5.73 & 22,781 & 16.26 & 61,906 & 42.61 & 21,433 \\
\hline
\end{tabular}

Significant level ${ }^{* * *} p<0.001 ;{ }^{* *} p<0.01 ;{ }^{*} p<0.05$

$\mathrm{n}$ is un-weighted sample

who faced physical and emotional violence. The analysis reveals that the nearly 61 percent of the physically battered and 53 percent of the sexually abused women had experienced abortion. Similarly, the likelihood of experiencing termination of pregnancy was higher among women who experienced physical and sexual violence. The problems such as sexually transmitted diseases (STI) in the last 12 months and prolonged labour during pregnancy were positively associated with spousal violence, which affects the sexual and reproductive health of women. The risk of prolonged labour during pregnancy was significantly higher among women who experienced physical, sexual, and emotional violence. The multivariate adjusted model, shows that the risk of STIs is $77 \%$ higher among women who experienced any sexual violence $(\mathrm{AOR}=1.77,95 \% \mathrm{CI} 1.47,2.1)$ and $44 \%$ higher among women who experienced any emotional violence $(\mathrm{AOR}=1.44,95 \% \mathrm{CI} 1.23,2.67)$.

\section{Discussion}

The present study explores the level of spousal violence experienced by the women in India and its consequences on the sexually transmitted diseases, prolonged labour, unwanted pregnancy, abortion, ever had a termination of pregnancy and miscarriages [24, 25]. This study reveals that one among three women experienced any kind of violence in India by her partner or husband, which is on the same line with other studies $[1,23,26]$. The study further focuses on any type of spousal violence given by various socio-demographic, economic and other covariates backgrounds. All factors were significantly associated with physical, sexual and emotional spousal violence $[27,28]$. Moreover, this study has also extended the prevalence based analysis at the state level for any spousal violence. The state-level spousal violence revealed that northeast region states (Manipur, and Aruanachal Pradesh), eastern states (Bihar, Uttar Pradesh and other) and southern (Telangana, Andhra Pradesh, Tamil Nadu) shows higher prevalence compared to the national level and other states of India.

The violence against women could significantly affect women's physical, mental, and sexual health. The present study indicates that women who experienced any physical, sexual and emotional violence are more likely to have abortion, which is on the same line with other studies conducted in different regions $[13,14,29]$; the risk of unintended pregnancies is 1.72 times higher among women who experienced any sexual spousal violence, and this results is mentioned in previous studies $[5,30,31]$. Women who faced sexual and emotional violence are at higher risk of STI Infections which are in line with similar studies [12, 32, 33]. When we discuss about the risk of prolonged labour during pregnancy delivery observed higher among battered women in India [34]. This study also demonstrates the higher prevalence of unwanted pregnancy and ever had a pregnancy termination among women those who experienced physical or sexual violence in their married life by husband $[11,35]$. 
Table3 The association for the health consequences on women and exposure of physical, sexual, and emotional violence in India

\begin{tabular}{|c|c|c|c|c|c|c|c|c|c|c|c|c|}
\hline \multirow[t]{2}{*}{ Exposure of violence } & \multicolumn{3}{|c|}{ STI (in last 12 months) } & \multicolumn{3}{|c|}{ Unwanted pregnancy } & \multicolumn{3}{|c|}{ Abortion } & \multicolumn{3}{|c|}{$\begin{array}{l}\text { Ever had a termination of } \\
\text { pregnancy }\end{array}$} \\
\hline & AOR & \multicolumn{2}{|c|}{ 95\% C.I } & AOR & \multicolumn{2}{|c|}{ 95\% C.I } & AOR & \multicolumn{2}{|c|}{$95 \%$ C.I } & AOR & \multicolumn{2}{|c|}{ 95\% C.I } \\
\hline No & 1 & & & 1 & & & 1 & & & 1 & & \\
\hline Yes & 1.11 & 0.97 & 1.27 & 1.22 & 0.94 & 1.57 & $1.61^{* * *}$ & 1.36 & 1.91 & $1.43^{* * *}$ & 1.35 & 1.50 \\
\hline \multicolumn{13}{|l|}{ Emotional } \\
\hline No & 1 & & & 1 & & & 1 & & & 1 & & \\
\hline Yes & $1.44^{* * *}$ & 1.23 & 1.67 & 1.01 & 0.72 & 1.41 & $1.36^{* *}$ & 1.10 & 1.66 & $1.18^{* * *}$ & 1.10 & 1.25 \\
\hline \multicolumn{13}{|l|}{ Sexual } \\
\hline No & 1 & & & 1 & & & 1 & & & 1 & & \\
\hline Yes & $1.77^{* * *}$ & 1.47 & 2.10 & $1.72^{* *}$ & 1.19 & 2.50 & $1.53^{* * *}$ & 1.20 & 1.93 & $1.24^{* * *}$ & 1.14 & 1.34 \\
\hline \multicolumn{13}{|l|}{ Place of residence } \\
\hline Urban & 1 & & & 1 & & & 1 & & & 1 & & \\
\hline Rural & 1.06 & 0.94 & 1.20 & 1.22 & 0.92 & 1.61 & 0.87 & 0.74 & 1.03 & $0.87^{* *}$ & 0.82 & 0.91 \\
\hline \multicolumn{13}{|l|}{ Wealth index } \\
\hline Poorest & 1 & & & 1 & & & 1 & & & 1 & & \\
\hline Poorer & $1.45^{* * *}$ & 1.19 & 1.78 & 0.84 & 0.63 & 1.12 & $1.52^{* *}$ & 1.19 & 1.95 & $1.12^{* *}$ & 1.05 & 1.21 \\
\hline Middle & $1.83^{* * *}$ & 1.51 & 2.23 & 0.80 & 0.60 & 1.08 & $1.99^{* *}$ & 1.56 & 2.54 & 1.08 & 1.00 & 1.16 \\
\hline Richer & $2.09^{* * *}$ & 1.70 & 2.55 & $0.56^{* *}$ & 0.39 & 0.79 & $2.27^{* *}$ & 1.76 & 2.92 & $1.13^{* *}$ & 1.05 & 1.22 \\
\hline Richest & $2.67^{* * *}$ & 2.16 & 3.30 & $0.43^{* * *}$ & 0.28 & 0.64 & $2.11^{* *}$ & 1.58 & 2.79 & $1.16^{* *}$ & 1.06 & 1.26 \\
\hline \multicolumn{13}{|l|}{ Religion } \\
\hline Hindu & 1 & & & 1 & & & 1 & & & 1 & & \\
\hline Muslim & 0.99 & 0.84 & 1.15 & $1.72^{* * *}$ & 1.32 & 2.21 & 0.89 & 0.73 & 1.09 & $1.21^{* * *}$ & 1.13 & 1.28 \\
\hline Christians & 0.63 & 0.43 & 0.94 & 0.42 & 0.14 & 1.24 & 0.70 & 0.42 & 1.19 & 0.90 & 0.78 & 1.04 \\
\hline Others & 0.87 & 0.63 & 1.18 & 1.09 & 0.51 & 2.34 & 0.69 & 0.41 & 1.16 & $0.86^{*}$ & 0.74 & 0.98 \\
\hline \multicolumn{13}{|l|}{ Caste } \\
\hline OBC & 1 & & & 1 & & & 1 & & & 1 & & \\
\hline SC/ST & 1.14 & 1.00 & 1.30 & 1.01 & 0.79 & 1.30 & 0.89 & 0.75 & 1.07 & $0.95^{*}$ & 0.89 & 1.00 \\
\hline Others and don't know & 1.21 & 1.07 & 1.38 & 1.06 & 0.81 & 1.39 & 1.19 & 0.98 & 1.46 & $1.07^{*}$ & 1.01 & 1.13 \\
\hline
\end{tabular}

Ref: First category as the Ref Category with AOR 1: (AOR Adjusted Odds Ratio), C.I. 95\% confidence interval

P-value with level of significance: ${ }^{* *} p \leq 0.001 ;{ }^{* *} p \leq 0.01 ; * p \leq 0.05$

Cumulatively, as per the present study in the Indian context and existing studies in various subcontinents, it shown that there is an attributable impact of spousal violence on the health of ever-married women, specifically in reproductive and pregnancy [36]. These findings were based on cross-sectional data and opened the scope for further strong cohort-based experimental study. In India, the level of domestic and spousal violence has been a decline but still it at a higher level where one in three women are battered by her husband. It is still an issue of concern as its adverse consequences not only on the physical health of women but also mental and social health. Ongoing and existing studies were revealed that spousal violence is mainly experienced by a wife by her husband. A country like India, where the more prevalent nature of patriarchal society intends to women usually has a secondary place after her husband.
In Indian households, mostly in rural areas, it has been seen that men have been dominant women regarding decision making, facing injustice, oppression, suppression, and exploitation in male-dominated Indian society $[37,38]$. Therefore, in the subcontinent like, India should have multi-sectoral approaches in some kind of women empowerment, domestic violence law reforms and women security against spousal violence. In married women, reducing the level of such adverse reproductive and pregnancy problems can be reduced by the decline in the level of spousal violence against women in India.

\section{Conclusions}

This study provides evidence-based on population level survey data of abortion, currently unwanted pregnancies, sexual and reproductive health problems among married women and its association with IPV among women 
in India. The present study has included socio-economic and demographic indicators and other covariates such as children ever born, contraception use and intergeneration exposure to violence among women during their childhood, shown strong predictors of spousal violence. The analysis indicates that spousal violence exposure among ever-married women affects women's health, particularly the reproductive health and pregnancy outcomes which affected by physical, sexual or emotional abused. This study clearly indicates that sexual and physical violence contributed to the significant factor for pregnancies loss and unwanted pregnancies. Finally, to conclude this study, we can say that there is a significant difference in the health consequences or adverse pregnancy outcomes among battered and not battered women. Any form of spousal violence such as physical, sexual and emotional violence are increases the public health burden. The above results advocate that preventing physical, emotional and sexual IPV can improve maternal health and pregnancy outcomes among the ever-married women in India. In India, for preventing this, at the national and sub-national level should have multi-sectoral approaches such as women empowerment and higher education, strict law against domestic violence and women security.

\section{Limitation of the study}

This study has quite a few limitations that have to be acknowledged. This study is based on cross-sectional data and does not allow the sequencing of events to demonstrate a causal association. The data for the domestic violence of married women is too sensitive. It again depends on women's perception whether she provides information indeed or not about their sensitive private matter. A slap is unacceptable to some women, while for some other women, it may be acceptable, and hence, it would be under-reported. Spousal violence depends on many different social and community-level factors such as crime rates in society, government strictness, response to Women's crime reported by police and various things related to spousal violence, which not consider in NFHS-4 survey data. Apart from that, the question related to sexually transmitted infection is self-reported and not tested clinically. If available just after experiencing violence by women, the information about STI to women only for the last 12 months may give good results.

\section{Abbreviations \\ IPV: Intimate Partner Violence; NFHS: National Family Health Survey; AOR: Adjusted odds ratio; STI: Sexually transmitted infection.}

\section{Acknowledgements}

We acknowledge the NFHS-4 survey done by nodal agency International Institute for Population Sciences (IIPS), Mumbai, for providing the relevant data for this study.

\section{Authors' contributions}

All authors have read and agreed to the manuscript. MB: Study design, carried out the statistical analysis, interpretation and drafted the manuscript. RRS: Provided support to the study design, statistical analysis and helped to draft the manuscript. All authors reviewed the manuscript. Both authors read and approved the final manuscript.

\section{Funding}

No funding was received for this work. However, the analysis is part of the dissertation work during Master of Science of the first author (MB) under the supervision of author (RRS).

\section{Availability of data and materials}

The study's datasets are publicly available Demographic Health Survey (DHS) site.

\section{Declarations}

\section{Ethics approval and consent to participate}

Not applicable, this is a secondary based survey, and data is publicly available to use.

\section{Consent for the publication}

Not applicable for this paper.

\section{Competing interests}

All authors have no competing interests.

Received: 4 March 2021 Accepted: 7 October 2021

Published online: 01 November 2021

References

1. Garcia-Moreno C, Jansen HA, Ellsberg M, Heise L, Watts CH. Prevalence of intimate partner violence: findings from the WHO multicountry study on women's health and domestic violence. The Lancet. 2006;368(9543):1260-9.

2. International Institute for Population Sciences (IIPS) and ICF. 2017. National Family Health Survey (NFHS-4), 2015-16: India. Mumbai: IIPS. http://rchiips.org/nfhs/pdf/NFHS4/India.pdf.

3. Begum S, Dwivedi SN, Pandey A, Mittal S. Association between domestic violence and unintended pregnancies in India: findings from the National Family Health Survey-2 data. Natl Med J India. 2010;23(4):198.

4. Silverman JG, Decker MR, McCauley HL, Gupta J, Miller E, Raj A, Goldberg $A B$. Male perpetration of intimate partner violence and involvement in abortions and abortionrelated conflict. Am J Public Health. 2010;100(8):1415-7.

5. Cripe SM, Sanchez SE, Perales MT, Lam N, Garcia P, Williams MA. Association of intimate partner physical and sexual violence with unintended pregnancy among pregnant women in Peru. Int J Gynecol Obstet. 2008;100(2):104-8.

6. Collumbien M, Gerresu M, Cleland J. Unwanted births and unsafe abortions from non-use and use of ineffective methods of contraception. Report prepared for the World Health Organization Comparative Risk Assessment Working Group, Centre for Population Studies, London School of Hygiene and Tropical Medicine. 2004.

7. Pallitto CC, O'Campo P. Community level effects of gender inequality on intimate partner violence and unintended pregnancy in Colombia: testing the feminist perspective. Soc Sci Med. 2005;60(10):2205-16.

8. Stephenson R, Koenig MA, Acharya R, Roy TK. Domestic violence, contraceptive use, and unwanted pregnancy in rural India. Stud Fam Plan. 2008;39(3):177-86.

9. Acharya K, Paudel YR, Silwal P. Sexual violence as a predictor of unintended pregnancy among married young women: evidence from the 2016 Nepal demographic and health survey. BMC Pregnan Childb. 2019;19(1):196.

10. Kishor S, Johnson K. Reproductive health and domestic violence: Are the poorest women uniquely disadvantaged? Demography. 2006;43(2):293-307 
11. Stöckl H, Filippi V, Watts C, Mbwambo JK. Induced abortion, pregnancy loss and intimate partner violence in Tanzania: a population based study. BMC Pregnan Childb. 2012;12(1):12.

12. Stephenson R, Koenig MA, Ahmed S. Domestic violence and symptoms of gynecologic morbidity among women in North India. Int Fam Plan Perspect. 2006;66:201-8.

13. Silverman JG, Gupta J, Decker MR, Kapur N, Raj A. Intimate partner violence and unwanted pregnancy, miscarriage, induced abortion, and stillbirth among a national sample of Bangladeshi women. BJOG Int J Obstet Gynaecol. 2007;114(10):1246-52.

14. Silverman JG, Decker MR, Kapur NA, Gupta J, Raj A. Violence against wives, sexual risk and sexually transmitted infection among Bangladeshi men. Sex Transm Infect. 2007:83(3):211-5.

15. Rothenberg KH, Paskey SJ. The risk of domestic violence and women with HIV infection: implications for partner notification, public policy, and the law. Am J Public Health. 1995:85(11):1569-76.

16. Zakar R, Zakar MZ, Mikolajczyk R, Krämer A. Intimate partner violence and its association with women's reproductive health in Pakistan. Int J Gynecol Obstet. 2012;117(1):10-4.

17. Do HP, Tran BX, Nguyen CT, Van Vo T, Baker PR, Dunne MP. Inter-partner violence during pregnancy, maternal mental health and birth outcomes in Vietnam: a systematic review. Child Youth Serv Rev. 2019;96:255-65.

18. Ferdos J, Rahman MM, Jesmin SS, Rahman MA, Sasagawa T. Association between intimate partner violence during pregnancy and maternal pregnancy complications among recently delivered women in Bangladesh. Aggress Behav. 2018;44(3):294-305.

19. Straus MA. The conflict tactics scales and its critics: an evaluation and new data on validity and reliability. In Physical violence in American families. Routledge; 2017. p. 49-74.

20. Straus MA, Gelles R. Measuring intrafamily conflict and violence: the conflict. 1979

21. Croft TN, Marshall AM, Allen CK. Guide to DHS statistics. Rockville: ICF; 2018.

22. Anand E, Unisa S, Singh J. Intimate partner violence and unintended pregnancy among adolescent and young adult married women in south asia. J Biosoc Sci. 2017:49(2):206-21.

23. Krishnamoorthy Y, Ganesh K, Vijayakumar K. Physical, emotional and sexual violence faced by spouses in India: evidence on determinants and help-seeking behaviour from a nationally representative survey. J Epidemiol Community Health. 2020;6:66

24. Peedicayil A, Sadowski LS, Jeyaseelan L, Shankar V, Jain D, Suresh S, et al. Spousal physical violence against women during pregnancy. BJOG Int J Obstet Gynaecol. 2004;111(7):682-7.
25. Salam MA, Alim MA, Noguchi T. Spousal abuse against women and its consequences on reproductive health: a study in the urban slums in Bangladesh. Matern Child Health J. 2006;10(1):83-94.

26. WHO.'news-room/fact-sheets/detail/violence-against-women', World health organization. 2017. https://www.who.int/news-room/fact-sheets/ detail/violence-against-women.

27. Ahmad J, Khan N, Mozumdar A. Spousal violence against women in India: a social-ecological analysis using data from the National Family Health Survey 2015 to 2016. J Interpers Viol. 2019;6:66

28. Chauhan BG, Jungari S. Spousal violence in India: role of gender relative status. Demogr India. 2020;49(1):124-39.

29. Bola SL. Spousal violence and pregnancy termination among married women in Nigeria. Afr Health Sci. 2016;16(2):429-40.

30. Miller E, Jordan B, Levenson R, Silverman JG. Reproductive coercion: connecting the dots between partner violence and unintended pregnancy. Contraception. 2010;81(6):457-9.

31. Shabnam S, Mukherjee A. Spousal violence and unintended pregnancy in India: evidence from NFHS-3. Indian J Res Rep Med Sci. 2013;3(3):1-8.

32. Bauer HM, Gibson P, Hernandez M, Kent C, Klausner J, Bolan G. Intimate partner violence and high-risk sexual behaviors among female patients with sexually transmitted diseases. Sex Transm Dis. 2002;29(7):411-6.

33. Shabnam S. Sexually transmitted infections and spousal violence: the experience of married women in India. Indian J Gend Stud. 2017;24(1):24-46.

34. Dhar D, McDougal L, Hay K, et al. Associations between intimate partner violence and reproductive and maternal health outcomes in Bihar, India: a cross-sectional study. Reprod Health. 2018;15:109. https://doi.org/10. 1186/s12978-018-0551-2.

35. Sarkar NN. The impact of intimate partner violence on women's reproductive health and pregnancy outcome. J Obstet Gynaecol. 2008;28(3):266-71. https://doi.org/10.1080/01443610802042415.

36. Heise L, Ellsberg M, Gottemoeller M. Ending violence against women. Popul Rep. 1999;27(4):1-1.

37. Sawant TS. Place of the woman in Indian society: a brief review. J Humanit Soc Sci. 2016;21(9):21-5.

38. Singh R. Status of women in Indian society. In: The Paideia Archive: twentieth world congress of philosophy, vol 7; 1998. p. 47-50.

\section{Publisher's Note}

Springer Nature remains neutral with regard to jurisdictional claims in published maps and institutional affiliations.
Ready to submit your research? Choose BMC and benefit from:

- fast, convenient online submission

- thorough peer review by experienced researchers in your field

- rapid publication on acceptance

- support for research data, including large and complex data types

- gold Open Access which fosters wider collaboration and increased citations

- maximum visibility for your research: over $100 \mathrm{M}$ website views per year

At BMC, research is always in progress.

Learn more biomedcentral.com/submissions 